\title{
LA SUSTITUCIÓN DE LA NOCIÓN “TÍTULO-VALOR” POR "VALORES NEGOCIABLES" EN LA LEY DEL MERCADO DE VALORES DE ESPAÑA, COMO BASE PARA LA DELIMITACIÓN DE UN DERECHO DEL MERCADO DE VALORES ${ }^{*}$
}

\author{
Alejandro GuZMÁN BRITO** \\ JOSÉ LUIS GUERRERO BECAR ${ }^{* * *}$
}

RESUMEN: El derecho español entre los años 1988 y 2015 ha evolucionado para establecer una delimitación específica del mercado de valores y su objeto de contratación, influenciado por la normativa europea pero resguardando los consensos de la doctrina española sobre la denominación del mercado y su objeto de contratación, lo que permite dar por superada la indeterminación previa a 1988 para avanzar en la construcción de un derecho específico del mercado de valores, todo ello consolidado con una normativa sistemática actualmente regulada en el RDL 4/2015, lo cual genera una mayor seguridad jurídica para los partícipes del mercado.

PALABRAS CLAVE: Valores negociables; títulos-valores; instrumentos financieros; mercado de capitales, mercado de valores

\footnotetext{
* $\quad$ Fecha de recepción: 14 de marzo de 2016.

Fecha de aceptación: 15 de septiembre de 2016.

Este trabajo fue compuesto como parte del proyecto de investigación patrocinado por el Fondo de Investigación Científica y Tecnológica, con el título de "Los valores ante su depósito y eventual desmaterialización en el derecho chileno".

** Doctor en derecho. Profesor titular en la Facultad de Derecho de la Pontificia Universidad Católica de Valparaíso (Chile). Dirección postal: Avda. Brasil 2950, Valparaíso, Chile. Correo electrónico: alejandro.guzman@pucv.cl

*** Doctor en derecho. Máster en derecho y máster en administración de empresas. Profesor adjunto en la Facultad de Derecho de la Pontificia Universidad Católica de Valparaíso (Chile). Dirección postal: Avda. Brasil 2950, Valparaíso, Chile. Correo electrónico: jose.guerrero@ pucv.cl
} 


\section{THE SUBSTITUTION OF THE NOTION "SECURITIES" FOR “NEGOTIABLE SECURITIES" IN THE SPANISH SECURITIES MARKET LAW, AS A BASIS FOR THE DEFINITION OF A SECURITIES MARKET LAW}

ABSTRACT: Spanish law system, between 1988 and 2015, has evolved to establish a specific definition of the securities market and the object of negotiation, influenced by European regulations but guarding the consensus of the Spanish doctrine on the name of the market and the object of negotiation, allowing to overcome the prior uncertainty for 1988 to advance the construction of a specific law system of the securities market, all of it consolidated with systematic regulations currently established in the RDL 4/2015, which generates greater legal certainty for market participants.

KEY WORDS: Securities; financial instruments; capital markets; securities market

Sumario: Introducción. 1) Uso de la noción "mercado financiero" como referencia al mercado genérico y de las nociones "mercado de capitales" y "mercado de valores" como referencia a mercados especificos inicialmente indiferenciados. 2) Utilización progresiva y excluyente de la noción de "mercado de valores" en la doctrina española. 3) Avance de la doctrina española hacia una diferenciación entre las nociones de "mercados de capitales" y "mercados de valores". 4) Sobre la noción de "valores negociables" e "instrumentos financieros" en la legislación española. 5) Sobre el término "mercado de valores" en la legislación española. 6) Conclusión: Hacia un derecho del mercado de valores. Bibliografía.

\section{INTRODUCCIÓN}

En el derecho español, como en otros derechos, tradicionalmente se utilizó la expresión "títulos-valor" para denominar al objeto de operación en los mercados financieros. Estos últimos, a su vez, eran llamados indistintamente "mercados de capitales" y "mercados de valores" con referencia, pues, al mercado en que se negocian los "títulos-valor".

Esta nomenclatura comenzó a variar con la entrada en vigencia de la Ley del mercado de valores española No 24/88, de 28 de julio de 1988 (= LMV. 24/1988) recientemente derogada y sustituida por la que con- 
tiene el Real decreto legislativo $\mathrm{N}^{\circ}$ 4/2015, de 24 de octubre de 2015 (= LMV. RDL 4/2015) ${ }^{1}$.

Desde la entrada en vigor de la LMV. 24/1988, la doctrina había empezado a hablar, cada vez más uniformemente solo de "mercado de valores", para referirse al mercado en que se transan valores negociables; y de "valores" (a veces "valores negociables"), para mentar los objetos que se negocian en aquellos mercados, de modo de desplazar el uso de las denominaciones "mercado de capitales" y "títulos-valor".

El fenómeno consistente en sustituir la expresión "título-valor" comenzó a tomar fuerza desde que se introdujo en el derecho español la figura de la desmaterialización de los valores en el año $1974^{2}$, porque entonces la presencia de un "título" perdió importancia. La innovación fue incorporada en la LMV. 24/1988, que puso su acento en lo que esos títulos portaban, esto es, los valores o valores negociables mismos, más allá de si tienen o no tienen un sustento material, o sea, un título. Esta evolución normativa $^{3}$ tiene su hito más reciente en la LMV.RDL 4/2015.

El objeto de este trabajo es analizar cómo la evolución normativa española ha permitido consensuar sobre la denominación del mercado de valores y su objeto de contratación, permitiendo el desarrollo de un derecho específico, el derecho del mercado de valores, superando indeterminaciones semánticas iniciales.

\section{1) USO DE LA NOCIÓN “MERCADO FINANCIERO” COMO REFERENCIA AL MERCADO GENÉRICO Y DE LAS NOCIONES "MERCADO DE CAPITALES" $Y$ "MERCADO DE VALORES" COMO REFERENCIA A MERCADOS ESPECÍFICOS INICIALMENTE INDIFERENCIADOS}

En el derecho español, hasta ahora, existe cierta uniformidad en la doctrina acerca de la forma de denominar al mercado o conjunto de mer-

1 Ley No 24/88, de 28 de julio de 1988, en BOE número 181 de 29 de julio de 1988 y Real decreto legislativo $\mathrm{N}^{\circ} 4 / 2015$, de 24 de octubre de 2015, en BOE número 255 de 24 de octubre de 2015.

2 En España, la desmaterialización de los títulos fue introducida por el Decreto No 1.128, de 25 de abril de 1974, en BOE número 102 de 29 de abril de 1974. Hoy el procedimiento está regulado en los artículos 5 a 12 de la Ley No 24 sobre mercado de valores, de 28 de julio de 1988, en BOE número 181 de 29 de julio de 1988 complementados por el Real Decreto No 116 de 14 de febrero de 1992, en BOE número 44 de 20 de febrero de 1992. La expresión "anotación en cuenta", solo insinuada en el Decreto de 1974, fue completamente perfilada en la ley de 1988.

3 Sobre la evolución normativa sobre el mercado de valores hasta la Ley No 24/88 de 28 de julio de 1988, véase Uría Fernández, Francisco (2007) "La evolución normativa sobre mercado de valores”. En Uría Fernández, Francisco (coordinador): Régimen jurídico de los mercados de valores y de las instituciones de inversión colectiva. Madrid: La Ley, pp. 53-88. 
cados que operan en el sistema financiero o sector nominal de la economía; en este contexto se dice "mercado financiero".

José Cachón Blanco define al sistema financiero como "un conjunto de instituciones, mercados, activos y técnicas a través de los cuales se potencia el ahorro, se canaliza el ahorro hacia la inversión y se consigue un equilibrio entre ambas magnitudes". El sistema financiero, según este autor, consta de los siguientes elementos: i) Instituciones financieras que participan de la actividad; ii) Mercados financieros que son "el conjunto de oferta y demanda de ahorro e inversión así como los mecanismos que permiten la canalización del ahorro hacia la inversión y la obtención de un equilibrio entre ella"; y iii) activos financieros, que son "aquellos productos a través de los cuales las instituciones financieras reciben ahorro de los ahorradores o bien aquellas se lo ofrecen a personas o entidades que solicitan ahorro para financiar inversiones o gastos" 4 .

El mercado financiero, comprendería, pues, tres mercados o mercados sectoriales: el bancario, el de capitales o valores ${ }^{5}$ y el de seguros.

Conforme con lo anterior, el mercado financiero espańol se estructura en torno a la organización bancaria, el mercado de capitales o valores y las sociedades de capitalización y ahorro, dedicadas estas últimas, principalmente, a los seguros de vida y fondos de pensiones ${ }^{6}$.

En la doctrina jurídica española, tradicionalmente y hasta los primeros ańos siguientes a la emisión de la LMV. 24/1988, para referirse al derecho aplicable al mercado en que se transan valores se prefirió utilizar

4 Ver Cachón Blanco, José (1992) Derecho del mercado de valores. Tomo I. Madrid: Dykinson, pp. 13-14. En igual sentido, IbáŃEZ Jiménez, Javier (2009) "Contratación del mercado de valores”. En Bercovitz Rodriguez-Cano, R. (director), Moralejo Imbernón, N. - Quicios Molina, S. (coordinadores): Tratado de los contratos. Valencia: Tirant lo Blanch, V, p. 4.856, quien distingue entre sistema financiero y mercado financiero, entendiendo el sistema financiero como un conglomerado de instituciones caracterizado por un conjunto de mercado o centros de negociación; por los sujetos que operan en ellos; por el objeto de contratado (dinero, valores o instrumentos negociables) y, por sus propios negocios o contratos.

5 Utilizaremos, por ahora, la fórmula de denominación indiferenciada de "mercado de capitales" o "mercado de valores".

6 Para Jiménez SÁnchez, Guillermo J. - Díaz Moreno, Alberto (coordinadores) (2013): Derecho mercantil, 15a edición. Madrid: Marcial Pons, VI: "Contratación en el mercado de valores", p. 25. El mercado financiero se estructura alrededor del mercado de capitales o valores, de la organización bancaria y de las sociedades de capitalización y ahorro, dedicadas estas últimas, principalmente, a los seguros de vida y fondos de pensiones. En igual sentido, IbÁŃEz Jiménez (2009) 4.857, quien sostiene "El mercado de valores, capitales o instrumentos financieros negociables constituye uno de los tres subsistemas básicos de aquel sistema financiero junto al sistema bancario y sistema asegurador"; Abella Santamaría, Jaime (1995) La ordenación del mercado de valores, Un ordenamiento dinámico. Madrid: Tecnos, p. 30 quien, refiriéndose al derecho aplicable, dice "El derecho financiero incluye, además del Derecho del mercado de capitales o de valores, el derecho bancario y el Derecho de las entidades de capitalización y ahorro y de las operaciones realizadas por ellas". 
la denominación "derecho del mercado de capitales" y, por tanto, a su objeto de estudio se le denominaba "mercado de capitales", Como en este mercado se transan títulos-valores o valores en general, después se usó en forma indistinta, las denominaciones de "derecho del mercado de capitales" o "derecho del mercado de valores"7.

Más allá de las denominaciones recurridas, en lo que no existe discrepancia entre los autores es en que con "mercado de capitales" o "mercado de valores" se quiere denominar a uno o más submercados que forman parte del mercado general para el cual se reserva la denominación "mercado financiero".

El uso de la noción "mercado de capitales" con referencia al mercado en que se transaban valores negociables o tradicionalmente títulos-valores y, a partir de ello, la configuración de un denominado "derecho del mercado de capitales", tiene como referencia en la doctrina española a Alberto Bercovitz Rodríguez-Cano ${ }^{8}$, quien, siguiendo la doctrina alemana ( $\mathrm{Ka}$ pitalmarktrecht), abogó por el establecimiento de un derecho del mercado de capitales, como superador de la división tradicional, existente hasta la década del ochenta, entre el derecho de sociedades y el derecho bursátil ${ }^{9}$.

7 Por todos, véanse IbáÑez Jiménez (2009) 4.856; y Jiménez SÁnchez/Díaz Moreno (2013) 25.

8 Sobre la influencia de Alberto Bercovitz Rodríguez-Cano véase CACHón-Blanco (1992) 26. Igualmente, véase también el artículo de Abella Santamaría (1995) 30, en que señala "En 1988, consideraba que había llegado el momento de hablar de un nuevo derecho de mercado de capitales integrado por un conjunto de normas que tienen por objeto la regulación jurídica de los mercados de activos financieros negociables y que comprende, desde el punto de vista económico, tanto el mercado de capitales propiamente dicho como el mercado monetario, con exclusión del mercado del dinero en sentido estricto. Derecho financiero, Derecho de mercado de capitales y Derecho bursátil se presentan como tres círculos concéntricos".

9 Alberto Bercovitz Rodríguez-Cano declara que, previo a su trabajo, solamente ha encontrado "una referencia a las recientes insinuaciones a favor de un derecho del mercado de capitales, "Kapitalmarktrecht") al final de una nota a pie de página en el trabajo de ANíBAL SÁnchez, Andrés (1980) "En torno al concepto, evolución y fuentes del derecho bursátil en el sistema jurídico español". Revista de Derecho Mercantil, 155, p. 10. Véase Bercovitz Rodríguez-Cano, Alberto (1988) "El Derecho del mercado de capitales". Revista de Derecho Bancario y Bursátil, 8. Madrid, Centro de Estudios y Comunicación Económica, 29, pp. 68-69. Aníbal Sánchez Andrés, en la nota 2 del artículo antes mencionado, escribía "Las recientes insinuaciones en favor de un Derecho de Mercado de Capitales ("Kapitalmarktrecht"), que algunos autores vienen a calificar como un nuevo sector ("Rechtsgebiet") o dominio jurídico in statu nascendi (cfr. Kohl y Walz (1977) Kapitalmarktrecht als Aufgabe, en Die Aktiengesellschaft. Zeitschrift für das gesamte Aktienwesen, p. 29) resultan todavía minoritarias y, por el momento, no parece que puedan tener acogida entre nosotros". SánCHEz Andrés, Aníbal (1980) "En torno al concepto, evolución y fuentes del derecho bursátil en el sistema jurídico español. Revista de Derecho Mercantil, 155. Versión electrónica en Thomson Reuters-Aranzadi. BIB 1980\373, p. 3. 
Bercovitz señala que el contenido de los conceptos jurídicos debe considerar en primer término el contenido de los conceptos económicos, cuando estos se refieren a las mismas realidades y están previamente acuñados, y afirma que la referencia al mercado de capitales es habitual en el campo económico, pero que no está aceptada [a 1988] en el ámbito jurídico ${ }^{10}$. Por lo anterior, estima que en términos jurídicos debe utilizarse la denominación que se emplea en el ámbito económico.

Entonces, Bercovitz, para construir su visión sobre la cuestión, recurrió al ámbito económico, siguiendo a los economistas Luis Rodríguez, José Alberto Parejo, Álvaro Cuervo y Antonio Calvo ${ }^{11}$, quienes recogen la noción de "mercado de capitales" dada por el Comité de Transacciones Invisibles de la Organización para la Cooperación y el Desarrollo Económicos ${ }^{12}$, la cual entiende que el mercado de capitales comprende las operaciones de colocación y financiación a largo plazo y las instituciones que efectúan principalmente estas operaciones; $y$, conforme con esa noción, se entiende que es posible distinguir dos mercados: el de valores y el de crédito a largo plazo ${ }^{13}$.

De acuerdo con la noción de mercado de capitales que siguen estos economistas, el mercado de capitales se restringe a la colocación de valores y a la financiación o crédito de largo plazo; o sea, al mercado de emisión de valores o primario.

Estimamos que se incurre en un error cuando, al seguir esa noción restringida -colocación o emisión y financiación de largo plazo- luego se comprenda como parte del mercado de capitales a toda transacción de valores, ya sea en su emisión o posterior transacción, incluyendo, por tanto, al mercado secundario. También hay error cuando se concibe el crédito a largo plazo como algo distinto a la emisión de un valor, por cuanto, el crédito de largo plazo, entendiendo que se trata de un crédito bancario transferible, siempre se coloca $u$ ofrece en el mercado por medio de un valor que comenzará a circular, por ejemplo, a través de un bono.

En igual error creemos que incurre Cachón Blanco quien inicialmente diferencia las nociones de "mercado de capitales" y "mercado de valores", y después las considera como equivalentes. En efecto, ese autor

Bercovitz Rodríguez-Cano (1988) 70-71.

Véase recientemente: Rodríguez Saíz, L. - Parejo Gámir, J. - Cuervo García, A. - Calvo Bernardino, A. (2014) Manual de sistema financiero español, 25 edición. Barcelona: Ariel, p. 19.

12 Comité des Transactions Invisibles (1967) Études sur les marchés de capitaux. Rapport general. Paris: OCDE, p. 145 . No ha sido posible acceder al texto original de este documento.

13 Bercovitz Rodríguez-Cano (1988) 71-72. 
entiende por mercado de capitales: "Aquel mercado financiero que tiene por objeto la financiación de medio y largo plazo, tanto a través de activos financieros directos, como a través de valores mobiliarios a medio y largo plazo y de valores negociables con derechos de participación social. Es decir, el mercado de capitales comprende tanto el mercado crediticio a medio y largo plazo, como el mercado de valores en sentido estricto" 14 . Sin embargo, el mismo autor define al mercado de valores en sentido estricto como aquel que "tiene por objeto la emisión y negociación de valores negociables de financiación a medio y largo plazo, así como aquellos otros valores negociables que atribuyen derechos de participación en el capital social de una entidad o derechos de suscripción y de adquisición y venta de valores anteriores $\mathrm{u}$ otros instrumentos financieros basados en los mismos" 15 .

Como es posible apreciar, no existe inicialmente en la doctrina española una mayor distinción entre las nociones de mercados de capitales y mercado de valores, por lo que se termina reconociéndolas como denominaciones análogas pero con distinto significado, lo que aumenta la confusión $^{16}$.

\section{2) UTILIZACIÓN PROGRESIVA Y EXCLUYENTE DE LA NOCIÓN DE “MERCADO DE VALORES” EN LA DOCTRINA ESPAÑOLA}

Desde la entrada en vigor en España de la Ley del mercado de valores No 24/88, de 28 de julio de 1988, la doctrina espańola ha usado cada vez más frecuentemente la noción específica de "mercado de valores", para referirse al mercado en que se transan valores, sea primario o secundario, planteándose incluso la existencia de un específico derecho del mercado de valores ${ }^{17}$; todo ello en desmedro de la denominación "derecho del mercado de capitales" 18 .

A este respecto, la LMV. 24/1988 marcó una suerte de hito fundacional en cuanto al establecimiento en España de un derecho del mercado

\footnotetext{
14 Ver Cachón Blanco (1992) 16.

15 Cachón Blanco (1992) 15.

16 Cachón Blanco (1992) 16, lo declara expresamente al señalar que. "Los diferentes autores utilizan denominaciones análogas pero con distinto significado. Sea cual sea la denominación, lo importante es comprender el concepto que subyace bajo la misma. En particular, lo que hemos definido como 'mercado de valores', es calificado por Alberto Bercovitz (El Derecho del mercado de capitales, Revista de Derecho Bancario y Bursátil, 29, 1988) como 'mercado de capitales', pero con contenido análogo".

17 Sobre la existencia del Derecho del mercado de valores español, véase Abella Santamaría (I 995 ) 29-41; CaChón Blanco (1992) 25-56.

18 Ver Abella Santamaría (i995) 17-18.
} 
de valores, superador, por su ambición y ámbito de actuación, al anteriormente llamado "derecho bursátil" ${ }^{19}$, pero sin que se pueda distinguir claramente una diferencia inicial con el anteriormente denominado "derecho del mercado de capitales".

Abella Santamaría, es enfático en señalar que "con la Ley del mercado de valores -se refiere a la LMV. 24/1988- nace una nueva disciplina jurídica, denominada 'derecho del mercado de valores'. Este derecho es más amplio que el 'derecho bursátil' y aunque se identifique con el derecho del mercado de capitales, debe llamarse derecho del mercado de valores, por la denominación de la ley" ${ }^{20}$.

La LMV. 24/1988, tiene su punto de referencia en los artículos 67 a 73 del Tratado de la Comunidad Económica Europea ${ }^{21}$ y en las Directivas de 11 de mayo de $1960^{22}$, de 18 de diciembre de $1962^{23}$ y de 24 de junio de $1988^{24}$, disposiciones todas tendientes a lograr la libertad de circulación de capitales en los Estados miembros.

Posteriormente, ciertas reformas a la LMV. 24/1988 también han tenido como base la normativa europea, como la Directiva 93/6/CE, de 15 de marzo de 1993, sobre la necesidad de construir un mercado financiero único ${ }^{25}$, que condujo a la modificación de la LMV. 24/88 por la Ley $\mathrm{N}^{\circ} 37 / 1998^{26}$. Igualmente la Directiva 97/5/CE, relativa a transferencias

Abella Santamaría (1995) 17.

Abella Santamaría (1995) 29-30.

Las normas del Tratado Constitutivo de la Comunidad Económica Europea [luego sustituido por el Tratado de Funcionamiento de la Unión Europea] se referían a la liberalización del movimientos de capitales entre los Estados miembros. En el artículo 68,2 Trat. CEE, se señalaba "Cuando un Estado miembro aplique a los movimientos de capitales liberalizados con arreglo a las disposiciones del presente Capitulo su regulación interna relativa al mercado de capitales y al crédito, procederá en forma no discriminatoria". Cabe notar que esta norma distingue al mercado de capitales del mercado del crédito, aun cuando en ambos es posible realizar la movilidad de capitales. Disponible en su versión en francés en: http://eur-lex.europa. eu/legal-content/FR/TXT/PDF/?uri=CELEX:11957E/TXT\&from=ES [Fecha de visita: 30 de agosto de 2016]. Esta normativa europea, impulsó a España luego de su incorporación en la Comunidad Económica Europea en 1986 [posteriormente Unión Europea] a reformar su normativa interna. Primera Directiva del Consejo para la aplicación del artículo 67 del Tratado, de 11 de mayo de 1960, en Diario Oficial de las Comunidades Europeas núm. 43 de 12 de julio de 1960. Segunda Directiva del Consejo para la aplicación del artículo 67 del Tratado, de 18 de diciembre de 1962 en Diario Oficial de las Comunidades Europeas núm. 10 de 22 de enero de 1963.

24 Directiva 88/361/CEE del Consejo de 24 de junio de 1988 para la aplicación del artículo 67 del Tratado, en Diario Oficial de las Comunidades Europeas núm. L 178 de 8 de julio de 1988.

25 Directiva 93/6/CEE del Consejo de 15 de marzo de 1993 sobre la adecuación del capital de las empresas de inversión y las entidades de crédito, en Diario Oficial de las Comunidades Europeas núm. L 141 de 11 de junio de 1993.

26 Véase Jiménez Sánchez/Díaz Moreno (2013) 30. 
transfronterizas $^{27}$ y la Directiva 2004/39/CE, relativa a los mercados de instrumentos financieros ${ }^{28}$ ha determinado enmiendas a la LMV.

El artículo 64,2 del Tratado de funcionamiento de la Unión Europea ${ }^{29}$, señala: "Aunque procurando alcanzar el objetivo de la libre circulación de capitales entre Estados miembros y terceros paises en el mayor grado posible, y sin perjuicio de lo dispuesto en los demás capitulos de los Tratados, el Parlamento Europeo y el Consejo, con arreglo al procedimiento legislativo ordinario, adoptarán medidas relativas a los movimientos de capitales, con destino a terceros paises o procedentes de ellos, que supongan inversiones directas, incluidas las inmobiliarias, el establecimiento, la prestación de servicios financieros o la admisión de valores en los mercados de capitales" 30 .

Si bien el Tratado de funcionamiento de la Unión Europea hace referencia a "la admisión de valores en los mercados de capitales", no es posible presumir que se utilice "mercado de capitales" en términos genéricos ya que lo hace con referencia a la incorporación de valores a los mercados internos, por lo cual parece adecuado entender que se trata de su incorporación al mercado primario para permitir su primera colocación en el mercado interno, como se hace normalmente para obtener financiación en mercado externos, tal cual acaece con los "eurobonos" o las "euroacciones" 31 . Por supuesto, ello implica que luego los valores puedan transarse en el mercado secundario, pero ello no significa que ese mercado secundario de valores deba ser denominando como "mercado de capitales".

27 Directiva 97/5/CE del Parlamento Europeo y del Consejo de 27 de enero de 1997, en Diario Oficial de las Comunidades Europeas núm. L 43 de 14 de febrero de 1997.

28 Directiva 2004/39/CE del Parlamento Europeo y del Consejo de 21 de abril de 2004, en Diario Oficial de la Unión Europea núm. L 145 de 30 de abril de 2004.

29 Diario Oficial de la Unión Europea, número C 236 de 26 de octubre de 2012.

30 Otras referencias al mercado de capitales lo realiza el Tratado de Funcionamiento de la Unión Europea, a propósito del Banco Europeo de Inversiones, artículo 309, que permite que dicho banco recurra a los mercados de capitales. El artículo 20 de los "Estatutos del Banco [Protocolo $\mathrm{N}^{\circ}$ 5], dispone "1. El Banco tomará a préstamo en los mercados de capitales los recursos necesarios para el cumplimiento de su misión. 2. El Banco podrá tomar dinero a préstamo en el mercado de capitales de los Estados miembros, en el marco de las disposiciones legales aplicables a dichos mercados". Cabe hacer notar que en el mercado de valores secundario no es posible tomar préstamos, ya que allí las partes no buscan financiamiento en cuanto a la compra o venta del valor, sino que ambas buscan rentabilidad, uno al liquidar la inversión y otro al invertir en el valor para esperar una rentabilidad futura. Por lo seńalado, mercado de capitales en este contexto debiera referirse al mercado primario de valores y/o al mercado del crédito, pero no al mercado secundario de valores, respecto del cual nadie duda de denominarle, al menos, como mercado de valores en sentido estricto. En otras palabras, el Banco Europeo de Inversiones no puede obtener recursos en el mercado de valores secundario, por ejemplo en la Bolsa cuando se transen valores ya emitidos.

31 Sobre valores en el mercado financiero internacional, véase DíEz DE CASTRo, L. - MascaREÑAs, J. (1994) Ingeniería financiera. La gestión en los mercados financieros internacionales. Madrid: Mc Graw-Hill. 
No obstante la señalada uniformidad progresiva en el uso de la noción de "mercado de valores", aún es posible encontrar en algunos autores la utilización indistinta de las denominaciones "mercados de capitales" y "mercado de valores" 32 , lo que puede generar confusión al lego en la materia; de forma no poco frecuente, se prefiere pasar por alto la discusión en torno a la denominación si en definitiva está claro respecto sobre qué se habla. Como dice Cachón: "sea cual sea la denominación, lo importante es comprender el concepto que subyace bajo la misma" 33 . Por su lado, Javier Ibáñez Jiménez sostiene que la doctrina española "acoge indistintamente las expresiones mercado de 'valores' (nombre tomado de la LMV. [Ley 24/1988, de 28 de julio, del Mercado de valores y de la expresión clásica 'valores mobiliarios') y de 'capitales' (por la negociación de títulos emitidos por sociedades capitalistas" 34 .

En cuanto a la noción de "mercado bursátil", no hay dudas en la doctrina española que él es, a su vez, un submercado o mercado específico, bajo el entendimiento de que la transacción de valores se produce tanto en las Bolsas de Valores - mercado bursátil- como fuera de ellas ${ }^{35}$, lo cual explica que tradicionalmente se hablara de un derecho bursátil ${ }^{36}$.

\section{3) AVANCE de la doctrina ESPaÑola HaCia UNA DifERENCIACión ENTRE LAS NOCIONES DE “MERCADOS DE CAPITALES" $Y$ "MERCADOS DE VALORES"}

La doctrina española progresivamente ha intentado diferenciar las nociones de mercado de capitales y mercado de valores, entendiéndolas como nociones con características propias.

La diferenciación queda esbozada al reconocer, en el interior del mercado financiero, la existencia de "mercados primarios o de emisión"

32 Jiménez Sánchez/Díaz Moreno (2013) 30, señala que junto al mercado bancario y de seguros, se sitúa el mercado de capitales o mercado de valores en el que se puede incluir tanto al puro mercado de capitales como el mercado monetario.

33 Cachón Blanco (1992) 16. Es ilustrativo de esta situación la descripción que José Cachón Blanco realiza identificando cuatro definiciones sucesivas de mercado de capitales que ALberto Bercovitz Rodríguez-Cano, realiza en el artículo "Derecho del mercado de capitales”, el que luego según el propio Cachón Blanco hay que entenderlo en forma análoga al mercado de valores. Véase Bercovitz Rodríguez-Cano (1988) 75, 77, 80 y 96; y CaCHón BLANCO (1992) 26.

34 IbáŃEz Jiménez (2009) 4.856. En este punto el autor, sigue a Bercovitz RodríguezCano (1988).

35 Abella Santamaría (1995) 30, refiriéndose al derecho del mercado de valores, sostiene que "Este derecho es más amplio que el Derecho Bursátil y aunque se identifica con el derecho del mercado de capitales, debe llamarse Derecho del mercado de valores por la denominación de la ley”. En igual sentido, Bercovitz Rodríguez-Cano (1988) 68-69. Ver SÁnchez Andrés (1980) 7-70. 
-mercados principales-, entre los que se puede incluir el mercado de capitales y el mercado del dinero; y "mercados complementarios", entre los que se situarían los mercados de servicios financieros, los mercados secundarios y los mercados de derivados ${ }^{37}$.

$\mathrm{Si}$ consideramos que en los mercados secundarios y mercados de derivados financieros se transan valores negociables e instrumentos finan$\operatorname{cieros}^{38}$, podríamos entender que se insinúa una diferenciación entre un mercado primario o de emisión (de capitales y dinero) y un mercado secundario o de reventa (de valores e instrumentos financieros).

La Directiva 2004/39/CE ${ }^{39}$, en la sección C del Anexo I define los instrumentos financieros y comprende, además de los valores negociables, a los instrumentos del mercado monetario, los contratos de futuros, las opciones y los "swaps", entre otros.

Cachón Blanco intenta otra forma de diferenciación, bajo la fórmula de identificar como parte del mercado financiero a tres mercados: i) El mercado del crédito; ii) El mercado de valores en sentido amplio, que incluye al mercado de dinero o monetario, que es de emisión y negociación de activos financieros de corto plazo; y iii) El mercado de valores, en sentido estricto, que tiene por objeto la emisión y negociación de valores negociables de financiación a mediano y largo plazo, así como otros valores representativos de participación en capital social y adquisición y venta de valores anteriores $\mathrm{u}$ otros instrumentos financieros basados en los mismos ${ }^{40}$. A su turno, los mercados de valores - amplio o restringidotendrían dos manifestaciones diferenciadas: mercado primario o de emisiones y mercado secundario en que se negocian los valores ya emitidos. Los mercados primarios ofrecen financiación a entidades demandantes de fondos y los secundarios ofrecen liquidez ${ }^{41}$.

Respecto del derecho aplicable, para Cachón Blanco es posible distinguir entre derecho del mercado financiero, derecho del mercado crediticio, derecho del mercado de capitales y derecho del mercado de valores ${ }^{42}$. Llama la atención que este autor no diferencie claramente las nociones de "mercados de capitales" y "mercado de valores", si luego realiza una clara distinción entre el derecho del mercado de capitales y el derecho

Jiménez SÁnchez/Díaz Moreno (2013) 26-27.

La Directiva 2004/39/CE define a los instrumentos financieros, en la sección C del Anexo I, y comprende además de los valores negociables, a instrumentos del mercado monetario, contratos de futuros, opciones, swaps, entre otros.

Véase (n. 28)

Cachón Blanco (1992) 14-15.

Cachón Blanco (1992) 22.

Cachón Blanco (1992) 26. 
del mercado de valores ${ }^{43}$, por lo que el intento de diferenciación queda inconcluso.

La revisión de la Ley del mercado de valores nos sugiere ser posible identificar y distinguir un "mercado de valores de emisión" y otro "de valores de reventa", debiendo restringirse el uso de la noción de "mercado de capitales" al de emisión o primario, en que la finalidad de los emisores es su financiación de mediano y largo plazo, es decir, la búsqueda de capital para operar en el mercado.

La búsqueda de financiación de mediano y largo plazo es, en efecto, propia de la finalidad o del interés de quien emite un valor en el mercado primario; dicha financiación puede tener y generalmente tendrá por finalidad obtener recursos para financiar la actividad económica; tales recursos se identifican normalmente con el capital, no en cuanto capital ya existente o constituido en el emisor, sino como financiación de capital -que será proveído por excedentes monetarios o capitales sujetos a inversión- que, junto al trabajo, generan la actividad productiva. En dicho sentido, creemos que es posible denominar como "mercado de capitales" o "de financiamiento de capitales", solo al mercado primario en que se transan valores emitidos por primera vez ${ }^{44}$.

\section{4) SOBRE LA NOCIÓN DE “VALORES NEGOCIABLES” E “INSTRUMENTOS FINANCIEROS” EN LA LEGISLACIÓN ESPAÑOLA}

Como se ha señalado, la doctrina española, desde la emisión de la LMV. 24/1988, ha optado en forma cada vez más constante por el uso de la expresión "mercado de valores", sosteniendo la existencia de un derecho

Cachón Blanco (1992) define el derecho del mercado de valores como "conjunto de normas que regulan las instituciones intervinientes en este mercado, los activos propios del mismo, y las operaciones que se realizan en él".

44 Sánchez Andrés, Aníbal (1999) "Nueva legislación del Mercado de Valores (observaciones preliminares al anteproyecto de 1985)". Revista de Derecho Bancario y Bursátil, 18. Madrid 73, pp. 74-75, a propósito de la utilización de conceptos económicos con connotaciones jurídicas, señala que "Si preguntamos a un economista qué se esconde bajo esa denominación sintética de "activos financieros" es probable que nos haga una extensa relación de figuras que van desde las más tradicionales (títulos de la deuda pública, acciones y obligaciones de sociedades) a las más nuevas y sofisticadas (participaciones en créditos sindicados o incluso en la deuda externa a base de documentos transferibles entre bancos) pasando por otras categorías intermedias, como pueden ser certificados de depósito, pagarés de empresa, etc. Se trata pues de un concepto muy elástico en el que la existencia de una relación obligatoria de contenido económico, susceptible, pues, de producir una rentabilidad y ser objeto de tráfico en base a una documentación ad hoc (que no siempre tendrá el significado de un título-valor en sentido estricto) es bastante para formar parte de una categoría que aún puede llegar a extenderse más, si desde el ámbito de las actividades inversoras nos trasladamos a los aledaños de las operaciones especulativas. 
del mercado de valores. Lo anterior ya se afirmaba en el texto de la LMV. RDL. 4/2015.

La LMV. 24/1988 utilizó, ya en su "Expresión de motivos" la denominación "mercado de valores" 45 para referirse al objeto de regulación de la ley; pero, al utilizar la expresión en plural, reconocía la existencia de varios mercados de valores: "La presente Ley pretende abordar esos múltiples y variados problemas asociados con la ordenación vigente de nuestros mercados de valores" 46 . Sin embargo, el párrafo siguiente vuelve a proponer la existencia de un mercado de valores único y, además, indiferenciado del mercado de capitales, cuando expresó: "Otro objetivo básico de esta Ley consiste en la necesidad de potenciar nuestro mercado de valores, ante la perspectiva, en 1992, de un mercado europeo de capitales y de una toma previa de posiciones a este respecto por diversos Estados miembros de la Comunidad Económica Europea. El objetivo final es que nuestro mercado de valores esté en condiciones apropiadas cuando dicho mercado europeo llegue a ser una realidad" 47.

Esto significa que el objetivo de la LMV. 24/1988 era que el mercado de valores español estuviese en condiciones apropiadas para cuando el mercado europeo de capitales llegare a ser una realidad, pero la frase recién mencionada de la "Expresión de motivos" de la ley es confusa, porque utiliza denominaciones distintas: mercado de valores español para ser parte del mercado de capitales europeo, y no mercado de valores espańol para ser parte del mercado de valores europeo.

En cuanto al objeto de contratación del mercado, la LMV. 24/1988 sí tomó posición al señalar en su "Exposición de motivos" que: "La Ley reposa sobre el concepto de 'valores' o, para mayor precisión, de 'valores negociables', concepto difícil de definir de forma escueta en el articulado de un texto legal, pero no por ello carente de realidad. Así, se abandona, ante todo, la relación biunivoca dominante hasta hoy entre el mercado de valores y los "títulos-valores".

Esta toma de posición que realiza el legislador español es importante para poder uniformar la denominación que ha de otorgarse al objeto de contratación o transacción del mercado de valores, puesto que se opta por la noción "valores negociables" y, consecuentemente, por la denominación de "mercado de valores", dejando atrás, para efectos de este mercado,

\footnotetext{
45 La expresión de motivos de la LMV. 24/1988 de 28 julio, hace mención a la Comisión para el Estudio del Mercado de Valores creada en 1978 y a la necesidad de una reforma del mercado de valores.

46 Véase la "Expresión de motivos" LMV. 24/1988 de 28 de julio.

47 Véase la "Expresión de motivos" LMV. 24/1988 de 28 de julio.
} 
la noción títulos-valores y, en especial, las denominaciones de "mercado de capitales" y "mercado de valores".

El cambio de la noción de "títulos-valor" a "valores negociables" se entiende en cuanto la noción de "título" deja de ser un elemento característico del objeto de contratación en estos mercados, ya que la ley incorpora la posibilidad de que existan valores que consten no en un título sino que en anotaciones en cuenta, sin materialidad física por tanto, que antes caracterizaba a los valores, debido a lo cual se les denominaba "títulos-valor".

Si el objeto de transacción son los valores negociables, entonces parece razonable que el mercado en que se realiza la transacción se denomine "mercado de valores". También podría estimarse que la denominación fuere la de "mercado de valores negociables"; pero cabe entender que si los valores son negociables es porque se transan en un mercado, por lo que puede entenderse sin más que la expresión "mercado" comprende que lo que se transa en él es negociable. Si un valor fuere innegociable o incomerciable, no existiría mercado respecto de ese valor, y no tendría sentido referirnos a un mercado de valores innegociables.

La LMV. 24/1988 dejó claro la preferencia por la noción de "valores o valores negociables", en sustitución de la de "título-valor", en sus dos primeras normas: El artículo 1: "La presente ley tiene por objeto la regulación de los mercados primarios y secundarios de valores [...]"; y el artículo 2: "Quedan comprendidos en el ámbito de la presente Ley los valores negociables emitidos por personas o entidades públicas o privadas, y agrupados en emisiones. Reglamentariamente se establecerán los criterios de homogeneidad en virtud de los cuales un conjunto de valores negociables se entenderá integrado en una emisión".

Es, por tanto, la LMV. 24/1988 la que ha dejado a un lado la noción de "título-valor" e incorporado la de "valor negociable"; e introducido oficialmente la denominación "mercados de valores" sean primarios o secundarios. El uso de la expresiones en plural no es baladí, ya que da cuenta de poder existir distintos mercados de valores, sean primarios o de emisión o secundarios o de reventa.

La LMV. 24/1988, atendida la evolución de los mercados y el desarrollo de nuevos objetos de transacción, así como la necesidad de armonizar el derecho español con las Directivas de la Unión Europea en estas materias, ha sido objeto de diversas modificaciones, más de cuarenta entre 1988 y 2014; entre ellas destaca la realizada en los ańos 2007 y 2015, el año 2007 por la Ley 47/2007, de 19 de diciembre de 2007, que incorporó al ordenamiento jurídico español diversas Directivas europeas, entre otras, la directiva 2004/39/CE de 21 de abril de 2004 relativa a los 
mercados de instrumentos financieros ${ }^{48}$, y luego el año 2015 con el texto refundido de la Ley de mercado de valores (LMV. RDL 4/2015, que ha entrado en vigencia el 13 de noviembre de 2015). Este texto refundido no solo armoniza la legislación dispersa sino que, al amparo de una delegación legislativa, ha aprovechado para mejorar la sistemática del texto y ajustar algunas discordancias ${ }^{49}$.

Con la incorporación de la normativa europea a la Ley de mercado de valores, en particular con la LMV. 47/2007, se introduce en el ordenamiento jurídico español la noción de "instrumentos financieros" como objeto de contratación en el mercado de valores. Ellos comprenden a los valores negociables pero, además, a los contratos de derivados financieros como futuros, opciones, permutas financieras de tipos de interés a plazo y contratos de instrumentos financieros derivados relacionados con valores, divisas tipos de interés o rendimientos, entre otros, que se mencionan en un catálogo de valores negociables e instrumentos financieros. De esta forma, desde el año 2007 la Ley de mercado de valores ya no tiene como objeto de contratación exclusivamente a los valores negociables, sino a una noción más amplia de instrumentos financieros, que comprende, por cierto, a los valores negociables, pero también a otros instrumentos como los derivados financieros. De esta forma, los valores negociables son instrumentos financieros, pero no todos los instrumentos financieros serían valores negociables.

La Ley de mercado de valores desde el año 2007, pues, cambia el objeto de su regulación así como el objeto de contratación del mercado.

En lo relativo al objeto de regulación de la Ley de mercado de valores, desde el año 2007 se pasa desde "la regulación de los mercados primarios y secundarios de valores" a "la regulación de los sistemas españoles de negociación de instrumentos financieros". Luego, en el texto vigente de la LMV. RDL 4/2015, el objeto de su regulación se amplía aún más, pues comprende no solo los sistemas españoles de negociación de instrumentos financieros sino que se comprende a "los sistemas españoles de negociación, liquidación y registro de instrumentos financieros", incorporando por tanto a los sistemas de liquidación y registro de instrumentos financieros, antes no mencionados como objetos de regulación.

Por lo que atañe al objeto de contratación en el mercado de valores, también hubo una mudanza, pues la noción de "valores negociables" del texto original del artículo 2 de la LMV. 24/1988, que rezaba: “Quedan

\footnotetext{
Véase nota 28.

"Exposición de motivos" del Real Decreto Legislativo 4/2015 de 23 de octubre de 2015 por el que se aprueba el texto refundido de la Ley del mercado de valores.
} 
comprendidos en el ámbito de la presente Ley los valores negociables emitidos por personas o entidades públicas o privadas", fue modificado por la LMV. $47 / 2007$, a la de "instrumentos financieros", de modo que los "valores negociables" pasan a ser solo un tipo de estos últimos. En efecto, el artículo 2 de la LMV. 47/2007 estableció: "Quedan comprendidos en el ámbito de la presente ley los siguientes instrumentos financieros: 1. Valores negociables emitidos por personas o entidades, públicas o privadas, y agrupados en emisiones. Tendrán la consideración de valor negociable cualquier derecho de contenido patrimonial, cualquiera que sea su denominación, que por su configuración juridica propia y régimen de transmisión, sea susceptible de tráfico generalizado e impersonal en un mercado financiero; se considerarán en todo caso valores negociables, a los efectos de la presente Ley: a) Las acciones de sociedades y los valores negociables equivalentes a las acciones... [... ] 2. Contratos de opción, permutas, futuros [...]", con lo cual los valores negociables pasaron a ser un tipo o clase de instrumento financiero, junto a otros que detalla el artículo 2 de la LMV. 47/2007.

Con este nuevo texto, el legislador español, siguiendo la normativa europea, opta por establecer en el artículo 2 de la LMV. 47/2007, un catálogo de valores negociables, calificando como tales, entre otros, a las acciones, cuotas participativas de las cajas de ahorro, bonos y obligaciones y otros valores análogos, bonos de titulización, letras del tesoro y pagarés. Una vez terminado el catálogo de valores negociables, la norma continúa mencionando siete formas adicionales de instrumentos financieros, que ya no constituyen valores negociables, y que dicen relación con derivados financieros como lo son contratos de opciones, futuros y permutas finan$\operatorname{cieros}^{50}$.

A pesar del cambio del objeto de transacción del mercado, de valores negociables a instrumentos financieros, la ley que regula la negociación de estos instrumentos financieros, siguió denominándose Ley del mercado de valores, lo que nos parece adecuado porque, en sentido estricto, los instrumentos derivados que se incorporan como objeto de negociación en el artículo 2 no dejan de ser valores negociables, ya que son perfectamente asimilables al concepto general que ofrece la misma norma: "cualquier derecho de contenido patrimonial, cualquiera sea su denominación, que por su configuración propia y régimen de transmisión, sea susceptible de tráfico generalizado impersonal en un mercado financiero". En efecto, un contrato

50 A las permutas financieras, se les denomina "swaps" en el lenguaje financiero. Así también las denomina la Directiva 2004/39/CE “permutas (swaps)" 
de futuro, opción o permuta financiera ${ }^{51}$ cumplen perfectamente con la noción legal de "valor negociable", ya que contienen derechos de contenido patrimonial y son susceptibles de tráfico generalizado e impersonal en un mercado financiero, ya que se trata, por lo general, de contratos estandarizados para facilitar su transacción; no se ve razón alguna para no entenderlos comprendidos bajo el concepto de "valor negociables".

Una explicación de la exclusión de los derivados financieros como valores negociables en el artículo 2 LMV. española, señalándolos como un tipo específico de instrumento financiero, distinto a los valores negociables, es que esta norma incorpora la Directiva 2004/39/CE 52 en términos literales, y dicha normativa europea conlleva la necesidad de armonización con otros derechos en los que no se utiliza necesariamente la noción de "valores negociables" sino más bien de "instrumentos financieros". La Directiva se motiva en la conveniencia de "incluir en la lista de instrumentos financieros determinados instrumentos derivados sobre materias primas $y$ otros constituidos y negociados de un modo que plantea cuestiones de reglamentación comparables a las de los instrumentos financieros tradicionales" 53 .

Además, la noción de "valores negociables", de acuerdo con el artículo 6 LMV. RDL. 4/2015, puede representarse por medio de anotaciones en cuenta o por medio de títulos, debiendo la modalidad de representación elegida aplicarse a todos los valores integrados en una misma emisión. En todo caso, los valores admitidos a negociación en mercados secundarios oficiales o en sistemas multilaterales de negociación deberán estar necesariamente representados mediante anotaciones en cuenta, no existiendo la opción de representarlos mediante títulos.

Cabe hacer notar que los contratos de derivados financieros, como futuros, opciones o permutas financieras ("swaps"), se negocian en sistemas multilaterales de negociación, por lo que nuevamente no se ve razón para no comprender a estos como un tipo más de valor negociable.

Lo anterior se confirma en la propia LMV. RDL. 4/2015, cuyo artículo 64 dispone que podrán crearse mercados secundarios oficiales de futuros y opciones, de ámbito estatal, cuya representación sea la de anota-

51 Sobre los contratos de futuro y, en general, derivados financieros véanse Fernández, Pablo (1996) Opciones, futuros e instrumentos derivados. Barcelona: Deusto; Guerrero Becar, José Luis (2003) "Los contratos de futuro". Revista de Derecho de la Pontificia Universidad Católica de Valparaíso, № 24, pp. 277-319; Hull, John (2014) Introducción a los mercados de futuros y opciones, $8^{a}$ edición. México: Pearson Educación de México; Madrid Parra, Agustín (1994) Contratos y mercados de futuros y opciones. Madrid: Tecnos; Solar Díaz, María; Zazo García, María (1996) Futuros y otros instrumentos financieros derivados. Memoria de licenciatura Universidad de Chile.

$52 \quad$ Véase nota 28.

53 "Declaración de motivos" de la Directiva 2004/39/CE. 
ciones en cuenta. Si lo relacionamos con el artículo 6 de la misma LMV. RDL. 4/2015, son los valores negociables los que pueden representarse con anotaciones en cuenta, por lo que resulta ser claro que los futuros y opciones, que en el artículo 2, siguiendo la Directiva 2004/39/CE que los detalla como distintos a los valores negociables, en definitiva siguen siendo valores negociables.

En conclusión, es la Directiva 2004/39/CE la que obliga a incorporar la especie de los "valores negociables" al género de los "instrumentos financieros", definiendo a los primeros en su artículo 4,1,18 como: "Las categorías de valores que son negociables en el mercado de capitales, a excepción de los instrumentos de pago, como: a) acciones de sociedades y otros valores equiparables a las acciones de sociedades, asociaciones $u$ otras entidades y certificados de depósito representativos de acciones; b) obligaciones $u$ otras formas de deuda titulizada ${ }^{54}$, incluidos los certificados de depósito representativos de tales valores; c) los demás valores que dan derecho a adquirir o a vender tales valores negociables o que dan lugar a una liquidación en efectivo, determinada por referencia a valores negociables, divisas, tipos de interés o rendimientos, materias primas u otros indices o medidas" 55 .

El artículo 4,17 de la Directiva 2004/39/CE define los instrumentos financieros como aquellos especificados en la sección I, anexo C, donde se contiene una lista de instrumentos financieros; ella comienza con los valores negociables y luego enumera instrumentos monetarios, contratos de futuros, opciones, permutas (“swaps”) entre otros ${ }^{56}$, todos los cuales

Una deuda "titulizada" es denominada en el derecho chileno como deuda "securitizada" Directiva 2004/39/CE, nota 28.

Apartado I, sección C de la Directiva 2004/39/CE "Instrumentos financieros" "(1) Valores negociables [...] (2) Instrumentos del mercado monetario; (3) Participaciones de organismos de inversión colectiva; (4) Contratos de opciones, futuros, permutas ('swaps'), acuerdos de tipos de interés a plazo y otros contratos de derivados relacionados con valores, divisas, tipos de interés o rendimientos, $u$ otros instrumentos derivados, indices financieros o medidas financieras que puedan liquidarse en especie o en efectivo; (5) Contratos de opciones, futuros, permutas ('swaps'), acuerdos de tipos de interés a plazo y otros contratos de derivados relacionados con materias primas que deban liquidarse en efectivo o que puedan liquidarse en efectivo a petición de una de las partes (por motivos distintos al incumplimiento o a otro suceso que lleve a la rescisión del contrato); 6) Contratos de opciones, futuros, permutas ('swaps') y otros contratos de derivados relacionados con materias primas que puedan liquidarse en especie, siempre que se negocien en un mercado regulado o SMN [Sistema negociación multilateral] (7) Contratos de opciones, futuros, permutas ('swaps'), acuerdos de tipos de interés a plazo y otros contratos de derivados relacionados con materias primas que puedan ser liquidados mediante entrega física no mencionados en el punto 6 de la Sección $C$ y no destinados a fines comerciales, que presentan las características de otros instrumentos financieros derivados, teniendo en cuenta, entre otras cosas, si se liquidan a través de cámaras de compensación reconocidas o son objeto de ajustes regulares de los márgenes de garantía; (8) Instrumentos derivados para la transferencia del riesgo de crédito; (9) Contratos financieros por diferencias. (10) Contratos de opciones, futuros, permutas ('swaps'), acuerdos de tipos de interés a plazo y otros contratos de derivados relacionados con variables climáticas, gastos 
creemos que perfectamente se pueden comprender en la noción general de "valores negociables" que entrega el artículo 2 LMV. después de su modificación por la Ley 47/2007.

Sin embargo, la crítica que podemos dirigir al legislador español sobre la opción de sustituir la noción de "valores negociables" por aquella más amplia de "instrumentos financieros", es justo realizarla respecto de la Directiva 2004/39/CE más que a la ley española, por cuanto esta estuvo obligada a incorporar la normativa interna de tal Directiva. Por ello no resulta extraño que a pesar del cambio del objeto de contratación en la ley, que pasa de la noción de "valores negociables" a una más amplia de "instrumentos financieros", la ley siga denominándose del Mercado de valores y, a su vez, el mercado siga denominándose tal, no obstante los antecedentes previos del uso de una denominación indistinta de "mercado de capitales" y de "mercado de valores" y que la propia Directiva defina a los valores negociables como valores que se negocian en el mercado de capitales -y no de valores- (artículo 4,1,18 de la Directiva 2004/39/CE).

Al dejar de ser los "valores negociables" el objeto único de transacción en el mercado de valores atendida la sustitución por la noción de "instrumentos financieros", podría pensarse en ser necesario un cambio en la denominación del mercado mismo, de manera de pasar a llamarlo "mercado de instrumentos financieros" o "mercado financiero". Sin embargo, ello no ha sucedido. Lo anterior puede deberse a que en el derecho español no existe discusión, como anticipáramos en este trabajo, en cuanto a considerar al mercado financiero como una denominación amplia y genérica que comprenda a los distintos tipos de mercados, entre ellos al mercado en que se transen valores negociables o instrumentos financieros, siguiendo la nueva nomenclatura, pero también a los mercados de seguros y de crédito.

La Ley del mercado de valores de 2015, LMV. RDL. 4/2015 que ha entrado en vigor el 13 de noviembre de 2015, como señala su "Exposición de motivos" consolida la normativa española relativa al mercado de valores, lo que reafirma lo señalado previamente en orden a que el ordenamiento jurídico español siga utilizando la denominación "mer-

de transporte, autorizaciones de emisión o tipos de inflación u otras estadisticas económicas ofciales, que deban liquidarse en efectivo o que puedan liquidarse en efectivo a elección de una de las partes (por motivos distintos al incumplimiento o a otro suceso que lleve a la rescisión del contrato), asi como cualquier otro contrato derivado relacionado con activos, derechos, obligaciones, indices y medidas no mencionados en la presente sección $C$, que presentan las características de otros instrumentos financieros derivados, teniendo en cuenta, entre otras cosas, si se negocian en un mercado regulado o SMN, se liquidan a través de cámaras de compensación reconocidas o son objeto de ajustes regulares de los márgenes de garantía". 
cado de valores", tanto para el mercado mismo como para denominar a la ley que lo regula; y ello no obstante establecer como objeto de contratación a los instrumentos financieros y no a los valores negociables específicamente, ya que estos los considera parte del género de los "instrumentos financieros".

La opción de establecer un catálogo de instrumentos financieros, como el contenido en el artículo 2 LMV. RDL. 4/2015 proviene de la Directiva 2004/39/CE y de la LMV. 47/2007 que incorporó aquella Directiva en el derecho espańol, merced a su mera transcripción, salvo en un último punto en que la ley dispone: "El gobierno podrá modificar la relación de instrumentos financieros que figuren en este artículo 2 para adaptarlo a las modificaciones que establezca la Unión Europea", es decir, el elenco del artículo 2 viene a ser un listado o catálogo modificable para hacerlo coherente con las directivas europeas.

Queda claro que el derecho español, más allá de la incorporación de la Directiva 2004/39/CE, que opta por la noción de "instrumentos financieros", continúa con dar preeminencia a la noción de "valores negociables" y a la denominación de "mercado de valores", primario y secundario, por sobre la denominación de "mercado de capitales" que usa la propia Directiva o por sobre la denominación "mercados financieros" que pudo ser una alternativa de denominación a propósito de la introducción en la LMV. 47/2007 de la noción “instrumentos financieros" como su objeto de contratación general. La propia LMV. 47/2007 que incorporó los instrumentos financieros, en su "Exposición de motivos" responde este cuestionamiento, al señalar que, en cuanto a los mercados regulados españoles, se ha considerado conveniente mantener la expresión "mercados secundarios oficiales de valores", acuńado por la entonces vigente Ley del mercado de valores, al hallarse perfectamente arraigada en el ordenamiento jurídico español.

La preeminencia de la noción de "valores negociables" en la Ley del mercado de valores española por sobre la de "instrumentos financieros", incorporada por aplicación del derecho comunitario, queda clara en el artículo 3,1 LMV. RDL. 4/2015 -antes parte final de artículo 1 LMV. 47/2007- que señala: " $A$ los instrumentos financieros distintos a los valores negociables, les serán aplicables, con las adaptaciones que, en su caso, sean precisas, las reglas previstas en esta ley para los valores negociables". Por lo anterior, no obstante la incorporación de la noción de "instrumentos financieros", la propia ley española hace prevalecer la normativa aplicable a los valores negociables, lo que denota que el propio legislador espańol, más allá de la transcripción que se ve obligado a realizar de la Directiva 2004/39/CE, que define a los "valores negociables" como una especie de 
"instrumentos financieros", mantiene a los "valores negociables" como noción y denominación básicas concernientes objeto de contratación del mercado en la Ley de Mercado de Valores.

\section{5) SOBRE EL TÉRMINO “MERCADO DE VALORES” EN LA LEGISLACIÓN ESPAÑOLA}

En cuanto a la denominación del mercado en que transan los valores negociables, con la entrada en vigor de la LMV. 24/88, el ordenamiento jurídico español tomó una posición frente a la indeterminación existente entre el uso de las expresiones "mercado de capitales" y "mercado de valores”, y optó por una denominación específica y única que consta en la Ley del mercado de valores misma.

La LMV. 24/1988, en su texto original, distinguió claramente entre un "mercado primario de valores" 57 (título $3^{\circ}$, artículos 25 a 30 quáter) y uno "secundario" que denomina en plural "mercados secundarios oficiales" 58 (título $4^{\circ}$, artículos 31 a 61 ter) con lo cual la denominación de "mercado de valores" comprende a los mercados primario y secundario.

En lo que dice relación con el mercado primario de valores, este consiste en el mercado de emisión de valores, ya que el título $3^{\circ}$ del texto original de la ley, rubricado "Mercado primario de valores", regula precisamente la emisión de valores y establece el principio de libertad de su emisión y la intervención del Ministerio de Economía solo en determinadas emisiones como aquellas sujetas evolución de índices, deuda sobre un año, en moneda extranjera o emitidos por no residentes. Esta norma fue modificada por la Ley 5/2005, que reafirmó el principio de la libertad de emisión, pero estableció requisitos de registro en la Comisión Nacional del Mercado de Valores y exigió que los valores debían respetar el régimen jurídico al cual estuvieran sometidos y que serían libremente transmi-

57 Del artículo 25 párr. $1^{\circ}$ LMV. 24/1988 se desprende claramente que se trata del mercado de emisión de valores "Libertad de emisión, colocación de emisiones y requisitos de elegibilidad para la admisión a negociación en un mercado secundario oficial"

58 La LMV. 24/1988 sanciona a los mercados secundarios oficiales como mercados regulados. Son mercados regulados aquellos sistemas multilaterales que permiten reunir los diversos intereses de compra y venta sobre instrumentos financieros para dar lugar a contratos con respecto a los instrumentos financieros admitidos a negociación, y que están autorizados y funcionan de forma regular, conforme a lo previsto en este capítulo y en sus normas de desarrollo, con sujeción en todo caso, a condiciones de acceso, admisión a negociación, procedimientos operativos, información y publicidad. 
sibles (artículo 25 LMV.), lo que fue reiterado por el artículo $33 \mathrm{LMV}$. RDL. 4/2015.

En cuanto a los mercados secundarios de valores, estos operan con valores negociables ya emitidos en un mercado primario, y por ello también se les denomina "mercados de reventa".

La LMV. RDL. 4/2015, en su título 4º rubricado: "Mercados secundarios oficiales de valores", incorpora en su articulado la expresión "mercado regulado", con lo cual crea confusiones en cuanto pudiera tratarse de un mismo mercado o de mercados diferentes.

En las disposiciones generales de este título, el artículo 43 "Definición", en su numeral 1, no define a los mercados secundarios oficiales de valores sino que a los mercados regulados, transcribiendo para ello el artículo 4,1,11 de la Directiva 2004/39/CE59: "Son mercados regulados aquellos sistemas multilaterales que permiten reunir los diversos intereses de compra y venta sobre instrumentos financieros para dar lugar a contratos con respecto a los instrumentos financieros admitidos a negociación, y que están autorizados y funcionan de forma regular, conforme a lo previsto en este capitulo y en sus normas de desarrollo, con sujeción en todo caso, a condiciones de acceso, admisión a negociación, procedimientos operativos, información y publicidad".

Luego, en el artículo 43,2 la ley dispone que los mercados regulados españoles reciben la denominación de mercados secundarios oficiales, enumerando los mercados que la ley considera mercados secundarios oficiales: bolsas de valores, mercado de deuda pública en anotaciones, mercados de futuros y opciones, mercado de renta fija, cualesquiera mercados otros de ámbito estatal o autonómico debidamente autorizados. Por tanto, los mercados secundarios oficiales españoles, son mercados regulados

59 El artículo 4,1,14 de la Directiva 2004/39, relativa a los mercados de instrumentos financieros, define "mercado regulado" como "sistema multilateral, operado o gestionado por un gestor del mercado, que reune o brinda la posibilidad de reunir -dentro del sistema y según sus normas no discrecionales - los diversos intereses de compra y de venta sobre instrumentos financieros de múltiples terceros para dar lugar a contratos con respecto a los instrumentos financieros admitidos a negociación conforme a sus normas o sistemas, y que está autorizado y funciona de forma regular de conformidad con lo dispuesto en el título III'. La propuesta de Directiva sobre servicios de inversión y mercados regulados, presentada el 19 de marzo de 2002, explicitaba el concepto al señalar que "un 'mercado regulado' no solo consta de un lugar de negociación en el que se produce la negociación y el intercambio de instrumentos financieros con arreglo a unas normas que combinan diferentes tipos de características de negociación. Es más que esto contiene también una amplia gama de funciones, representa una forma de organización distinta, e integra caracteristicas particulares de negociación. La admisión de un instrumento a cotización en un 'mercado regulado' motiva también la aplicación de disposiciones de otras medidas legislativas conexas. Teniendo en cuenta estas consideraciones, la DSI considera que el funcionamiento de un 'mercado regulado' es una actividad que exige un régimen regulador diferente". 
en los términos de la Directiva 2004/39/CE, y si son regulados, entonces, constituyen sistemas multilaterales que permiten reunir los diversos intereses de compra y venta sobre instrumentos financieros.

Es importante precisar que no cabe confundir el término "mercado regulado" que utiliza la LMV. RDL. 4/2015 y que tiene un sentido técnico-financiero en la Directiva 2004/39/CE, con la noción de "mercados regulados" que se utiliza en el derecho administrativo o en el derecho económico para referirse a sectores de la economía que deben ser objeto de regulación jurídica especial o sectorial, por ejemplo, mercado pesquero, mercado eléctrico, mercado de servicios sanitarios, mercado bancarios, mercado de valores, etc.

La noción de "mercado regulado" que recoge el ordenamiento jurídico español de la Directiva 2004/39/CE tiene un sentido particular relacionado con la noción de "mercado organizado" 60 , esto es, mercados que tienen una organización en que operan una entidad administradora y miembros del mercados, transándose instrumentos estandarizados. Estos mercados establecen sus propias normas de funcionamiento, dentro de un marco jurídico general y se distinguen de los mercados no organizados $\mathrm{u}$ OTC (over the counter).

Así, por ejemplo, los mercados de derivados financieros del Mercado Español de Futuros Financieros $\left(\mathrm{MEFF}^{61}\right)$, renta fija o variable, en que se transan derivados financieros son mercados financieros organizados, más allá de la ley marco que los reconozca como mercados regulados o mercados secundarios oficiales, ya que estos mercados operan organizadamente ${ }^{62}$, aun sin un reconocimiento legal como mercados regulados u oficiales, ya que sin organización no es posible que estos mercados operen. Por ejemplo, la Bolsa de Valores, de acuerdo con el artículo 43,2 a) LMV. RDL. 4/2015, es un mercado regulado pero en el sentido de la Directiva 2004/39/CE, artículo 4,1,14, que es el concepto que reproduce el artículo 43,1 LMV., en cuanto es un sistema que requiere de un gestor del mercado, que reúne o brinda la posibilidad de reunir -dentro del sistema y según sus normas no discrecionales- los diversos intereses de compra y de venta sobre instrumentos financieros de múltiples terceros para dar lugar a contratos con respecto a los instrumentos financieros admitidos a nego-

60 La "Exposición de motivos" (6) de la Directiva 2004/39 menciona que es necesario definir "mercados regulados" y de sistema de negociación multilateral, y deben alinearse estrechamente entre sí para reflejar que cubren las mismas funciones de negociación organizada.

61 Se trata de un mercado secundario oficial que administra MEFF Sociedad Rectora de Productos Derivados S. A.

62 Véase Pellicer Trullen, Miguel (1992) Los mercados financieros organizados en España, en Servicio de Estudios Económicos, 50. Banco de España. 
ciación conforme a sus normas o sistemas, y que está autorizado y funciona de forma regular de conformidad con lo dispuesto en el título $3^{\circ} \mathrm{LMV}$.

La distinción efectuada nos permite entender el hecho que esta noción esté establecida en la LMV. RDL. 4/2015 dentro de las disposiciones generales del capítulo de los mercados secundarios oficiales y no dentro de las normas generales a toda la ley. De no efectuarse esta distinción cabría entender, erradamente, que el mercado primario o de emisión no sería regulado jurídicamente y que solo serían objeto de regulación los mercados secundarios oficiales, lo que no es sustentable, porque en el sentido general de la noción de "mercados regulados", todo el mercado de valores lo es, sea este primario o secundario.

Comprendiendo que el concepto derive de la normativa europea, creemos que la noción de "mercados regulados" que utiliza la ley española no es del todo adecuada, y es más precisa la noción de "mercados organizados" o simplemente de "mercados oficiales de valores". El propio legislador espańol aboga por la mantención de la denominación "mercados secundarios oficiales de valores", "acuñado por la Ley del Mercado de Valores, al hallarse perfectamente arraigado en nuestro ordenamiento juridico" 63 . A contrario, cabe comprender que la noción de "mercados regulados", está incorporada en la normativa española en función de la armonización del derecho de la Unión Europea, pero con primacía del uso de la noción "mercados secundarios oficiales" que es más precisa que la de "mercados regulados” posible de ser confundida con la noción de los sectores económicos regulados.

Cabe considerar que todos los mercados del ámbito financiero en que está comprometido el interés público, son o deben ser objeto de regulación. Por tanto, en sentido amplio, son siempre mercados regulados, lo que es una característica connatural en este ámbito económico ya que los efectos de las transacciones afectan el interés público macroeconómico.

Sin embargo, algunas transacciones deben realizarse para preservar y supervisar el cumplimiento de ciertos principios o reglas de funcionamiento, tales como transparencia, eficiencia $u$ otros, en un mercado especialmente configurado, en un mercado oficial, formal, organizado o establecido.

En dicho sentido, es más precisa la denominación "mercados oficiales", que la LMV. RDL. 4/2015 reconoce cuando expresa en el artículo 43,2: "Los mercados regulados españoles reciben la denominación de mercados secundarios oficiales". Luego, identifica a estos mercados, de la

“Exposición de motivos” de la Ley 47/2207 que modificó la LMV. 24/2008. 
siguiente manera: "Se considerarán mercados secundarios oficiales de valores los siguientes: a) Las Bolsas de Valores, b) el Mercado de Deuda Pública en Anotaciones, c) Los Mercados de Futuros y Opciones, cualquiera que sea el tipo de activo subyacente, financiero o no financiero, d) el Mercado de Renta Fija, $A I A F^{64}$, y e) Cualesquiera otros, de ámbito estatal, que, cumpliendo los requisitos previstos en el apartado 1, se autoricen en el marco de las previsiones de esta Ley y de su normativa de desarrollo, asi como aquellos, de ámbito autonómico, que autoricen las comunidades autónomas con competencia en la materia”.

Claramente esta norma se refiere exclusivamente a los mercados secundarios de valores oficiales, pues estos no son los únicos mercados secundarios existentes y hay mercados secundarios no oficiales o fuera de mercados organizados llamados "mercados OTC", lo que no implica que no sean objeto de regulación alguna; de allí la importancia de no confundir las nociones de "mercados organizados" como únicos mercados regulados, ya que, en sentido amplio, todos los mercados de valores, organizados o no, son objeto de alguna regulación, por lo que creemos que el legislador español de la LMV. 24/88 y sus modificaciones pudo ser más preciso señalando: "Los mercados de valores secundarios oficiales, son mercados regulados y se considerarán como tales, las operaciones de valores que se coticen en bolsas de valores ${ }^{65}$, de renta fija, de deuda pública en anotaciones, de derivados financieros cualquiera que sea el tipo de activo subyacente, financiero o no financiero [...]”.

\section{6) CONCLUSIÓN: HACIA UN DERECHO DEL MERCADO DE VALORES}

No cabe duda que la doctrina española, particularmente desde 1988, ha avanzado en la delimitación de la noción de "mercado de valores", al distinguir entre "mercados de emisión o primarios" y "de reventa o secundarios", y lo ha hecho a partir de una redefinición y reemplazo de la noción de títulos-valor", primero por "valores negociables" y luego por "instrumentos financieros" sin que se haya modificado la denominación de "mercado de valores", sean primarios o secundarios oficiales de valores, ya que estos términos se hallan perfectamente arraigados en el ordena-

\footnotetext{
64 AIAF Mercado español de referencia para la deuda corporativa y renta fija. Es un mercado organizado privado, cuyo gestor es AIAF Mercado de Renta Fija S.A., por lo que resulta curioso que se le mencione específicamente en la Ley del mercado de valores.

65 Cabe precisar que la Bolsa de Valores no es un mercado, sino una entidad, cuyo objeto es proveer las condiciones para que el mercado bursátil opere en ella.
} 
miento jurídico español como señala la exposición de motivos de una de las modificaciones de la LMV, la LMV 47/2007, generándose desde la LMV. 24/1988 hasta el texto refundido de la Ley del mercado de valores número 4/2015 un ordenamiento jurídico especial y flexible, que hoy se sistematiza en la LMV. RDL. 4/2015, donde se regula un mercado con características particulares que justifican una disciplina especial: el mercado de valores.

El mercado de valores ha quedado claramente delimitado en cuanto a su objeto de transacción: los valores negociables e instrumentos financieros definidos en el artículo 2 LMV RDL. 4/2015, los cuales pueden representarse en anotaciones en cuenta, con lo cual se supera la noción tradicional de "títulos-valor" y la indefinición previa a 1988 respecto a denominar indistintamente al mercado como "de capitales" o "de valores".

La noción de "valores negociables" y la expresión "mercados secundarios oficiales" se encuentran arraigados en el ordenamiento jurídico español, sin que la incorporación de la normativa europea, particularmente de la Directiva 2004/39/CE, que opta por la noción de "instrumentos financieros" y por la expresión "mercados regulados", hayan afectado ese entendimiento.

Lo anterior ha permitido que en el derecho español se haya avanzado en la construcción de un derecho específico del mercado de valores, que supere la noción inicial del derecho del mercado de capitales construida por los primeros autores, particularmente por Alberto Bercovitz Rodríguez-Cano, todo ello consolidado con una normativa sistemática que lo regula, lo cual genera una mayor seguridad jurídica para los partícipes del mercado.

\section{BibliografíA}

Abella Santamaría, Jaime (1995) La ordenación del mercado de valores, Un ordenamiento dinámico. Madrid: Tecnos.

Bercovitz Rodríguez-Cano, Alberto (1988) "El Derecho del mercado de capitales". Revista de Derecho Bancario y Bursátil, Vol. 8, No 29. Madrid: Centro de Estudios y Comunicación Económica, pp. 67-112.

Cachón Blanco, José (1992) Derecho del mercado de valores. Tomo I. Madrid: Dykinson.

Díez de Castro, Luis; Mascareñas, Juan (1994) Ingeniería Financiera. La gestión en los mercados financieros internacionales. Madrid: Mc Graw-Hill.

Fernández, Pablo (1996) Opciones, futuros e instrumentos derivados. Barcelona: Deusto. 
Guerrero Becar, José Luis (2003) "Los contratos de futuro". Revista de Derecho de la Pontificia Universidad Católica de Valparaíso, N²4, pp. 277-319.

Hull, John (2014) Introducción a los mercados de futuros y opciones, $8^{\mathrm{a}}$ edición. México: Pearson Educación de México.

IbáÑez JiméneZ, Javier (2009) "Contratación del mercado de valores". En Bercovitz Rodríguez-Cano, Rodrigo (director); Moralejo Imbernón, N.; Quicios Molina, S. (coordinadores): Tratado de los contratos. Valencia: Tirant lo Blanch.

Madrid Parra, Agustín (1994) Contratos y mercados de futuros y opciones. Madrid: Tecnos.

Pellicer Trullen, Miguel (1992) "Los mercados financieros organizados en España”. Servicio de Estudios Económicos, N 50, Banco de España.

Jiménez SÁnchez, Guillermo J.; Díaz Moreno, Alberto (coordinadores) (2013) Derecho mercantil, 15a edición. Madrid: Marcial Pons.

Rodríguez Sáiz, Luis; Parejo Gámir, José; Cuervo García, Álvaro; Calvo Bernardino, Antonio (2014) Manual de sistema financiero español, 25a edición. Barcelona: Ariel.

SÁnchez Andrés, Aníbal (1980) "En torno al concepto, evolución y fuentes del derecho bursátil en el sistema jurídico espańol". Revista de Derecho Mercantil, $\mathrm{N}^{\circ} 155$, pp. 7-70

Sánchez Andrés, Aníbal (1999) "Nueva legislación del Mercado de Valores (observaciones preliminares al anteproyecto de 1985)". Revista de Derecho Bancario y Bursátil, Año 18, N 73, pp. 67-84

Solar Díaz, María; Zazo García, María (1996) Futuros y otros instrumentos financieros derivados. Memoria de licenciatura Universidad de Chile.

Uría Fernández, Francisco (2007) "La evolución normativa sobre mercado de valores”. En Uría Fernández, Francisco (coordinador): Régimen juridico de los mercados de valores y de las instituciones de inversión colectiva. Madrid: La Ley. 